\title{
Genotype at Increased Risk of Developing Asthma After Tobacco Smoke Exposure
}

Wang C, Salam MT, Islam T, et al.: Effects of in utero and childhood tobacco smoke exposure and beta2-adrenergic receptor genotype on childhood asthma and wheezing. Pediatrics 2008, 122: e107-e114.

Rating: $\bullet$ Of importance.

Introduction: Variants in the $\beta_{2}$-adrenergic receptor gene may affect airway tone. The two most common single nucleotide polymorphisms in the $\beta_{2}$-adrenergic receptor gene are Arg16Gly and Glu27Gln. This trial attempted to determine whether functional variants in this gene affect the occurrence of wheezing.

Aims: The aim of this study was to investigate the joint effects of in utero and childhood secondhand tobacco smoke exposure and these two well-characterized single nucleotide polymorphisms of the $\beta_{2}$-adrenergic receptor gene on asthma and wheezing in white children.

Methods: Study patients participated in the Children's Health Study (1993-1996), which included schoolchildren from southern California. Data on asthma status, age at onset, wheezing history, sociodemographic information, and exposure history were collected from self-administered questionnaires completed by the parents/guardians of 3128 non-Hispanic and Hispanic white children. Buccal cells were collected as a source of genomic DNA.

Results: This study again found that in utero maternal smoking and exposure to secondhand tobacco smoke were associated with wheezing. Furthermore, individuals who were homozygous for the Arg16 allele and exposed to in utero maternal smoking were at a threefold increased risk of lifetime wheeze compared with children with no exposure or at least 1 Gly16 allele. A similar association was found with secondhand tobacco smoke and those homozygous for the Arg16 allele. No associations were found for Glu27Gln.

Discussion: The authors concluded that children exposed to in utero maternal smoking or childhood secondhand smoke are at increased risk for wheeze; the risk was greatest for those with the Arg16Arg genotype. The authors recommend taking tobacco smoke exposure into consideration when evaluating $\beta_{2}$-adrenergic receptor gene variation on respiratory outcomes.

\section{Comments}

The concept of personalized medicine uses genomic information to predict disease development and severity and response to medications. This article is an excellent introduction to the possibilities presented by this new frontier of medicine. Although reducing all children's exposure to environmental tobacco smoke is of the utmost importance, identifying those at highest risk could have a significant clinical impact in the future.

\section{Acknowledgment}

Drs. Christina E. Ciaccio and Jay M. Portnoy are affiliated with the Section of Allergy, Asthma, and Immunology at the Children's Mercy Hospitals and Clinics, where Dr. Ciaccio is an Assistant Professor of Pediatrics and Dr. Portnoy is the Chief of the Section of Allergy, Asthma, and Immunology and a Professor of Pediatrics. Correspondence should be sent to 2401 Gillham Road, Kansas City, MO 64108, USA. E-mail: ceciaccio@cmh.edu; jportnoy@cmh.edu.

\section{Disclosure}

No potential conflicts of interest relevant to this article were reported. 